\title{
Investigation on Flow Rule and Productivity in Poorly Consolidated Reservoirs
}

\author{
Wang Jing* and Liu Huiqing
}

Key Laboratory for Petroleum Engineering of the Ministry of Education, China University of Petroleum, Beijing 102249, China

\begin{abstract}
Based on the production data and statistical information of a practical oilfield, it is proved that the flow rule in wormhole or extra wormhole can be regarded as a high speed Non-Darcy flow, and used the Forchheimer equation to represent. The Forchheimer model is superior to the exponent model and Mazaheri model. Then, the productivity equation of poorly consolidated reservoir with wormhole is derived based on the Forchheimer eqation. Finally, the productivity equation is used to investigate the effect of viscosity ratio of crude oil to displacing fluid, the permeability ratio of wormhole to non-wormhole and injection-production pressure gradient on the yield percentage of the wormhole. The viscosity has the strongest effect on the yield distribution, and the injection-production pressure gradient has the weakest effect. Also, several improvement measures for enhancing oil recovery in poorly consolidated reservoirs with wormhole or extra wormhole are presented, such as polymer flooding, cross-linked polymer flooding, body gel blocking, pre-gelled particles flooding and foam flooding.
\end{abstract}

Keywords: poorly consolidated reservoir, wormhole, high speed Non-Darcy flow, productivity equation, enhanced oil recovery.

\section{INTRODUCTION}

Water flooding is a widely used method for field exploitation and secondary oil recovery all over the world. The success of any water flooding depends largely upon the ability of bank oil for efficient sweep to occur, regardless of the mobility ratio. However, after a long period of water flooding, the pore structure has been changed greatly, and the channeling is serious in the high and extra high permeability strip (namely wormhole and extra wormhole), which are formed in reservoirs. These strips make lots of injected water cyclically produced inefficiently along the wormhole, so that the utilization efficiency of the injected water is lower, and the swept volume reduced, and the oil recovery and development benefit is seriously affected [1-3]. At present, lots of matured oil fields are in the stage of high water-cut, utilization efficiency of injected water and development benefit is becoming lower. All these effects may have some relationship with the wormhole in the poorly consolidated reservoirs [4-6].

It is very necessary to strengthen the study on the wormhole to guide the development of poorly consolidated reservoirs at the high water-cut period for enhancing oil recovery. Many works have been done in the identification of wormhole such as forming influence factors, forming process and identification method [7-9]. The theory that fluids flow in wormhole is only restricted to the traditional percolation theory, or it is approximately regarded as pipe

Address coresspondence to this author at the center of 231\#, China University of Petroleum-Beijing, 18 Fuxue Road, Changping, Beijing, 102249, China; Fax: 86.10. 89733511; Tel: 86.15101173712;

E-mails: wangjing8510@163.com; jjdej77@sina.com flow. However, it is significant to understand the flow rule in the wormhole, because different flow rules will result in different development performances. Also, the flow rule is important for the reservoir numerical simulation. Therefore, in this paper the flow rule in the wormhole is studied based on the data from practical oilfield firstly. Then, the productivity equation of poorly consolidated reservoir with wormhole is obtained. Finally, sensitive analysis and improvement measure for development of poorly consolidated reservoirs are studied. This study is extremely significant to the development of poorly consolidated reservoir in the high water-cut period.

\section{FLOW RULE AND ITS CHARACTERIZATION IN THE WORMHOLE}

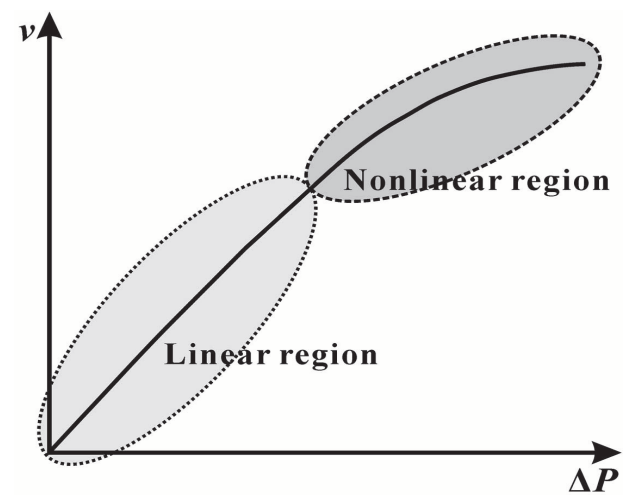

Fig. (1). Curve of velocity and pressure differential.

In general, the flow rule in the porous media obeys Darcy's law. However, as the speed increases, the relationship of pressure and speed deviates from the linearity 
and a curve appears in some cases, as shown in Fig. (1). The reason is that, when the speed is lower, the viscous resistance is the dominant force, and inertia force is so small that it can be ignored. At this moment, the pressure difference and speed represent a linear relation, which can be described by Darcy's law. When the speed is higher, the inertia force is so large that it can not be neglected. At this moment, the flow resistance is the sum of viscous resistance and inertia force, and the pressure difference and speed deviate from the linear relation.

When the wormhole or extra wormhole is existent in the poorly consolidated reservoir, the flow speed is high, and the Reynolds number is large, so a high speed Non-Darcy flow may appear, and modeled by a high speed Non-Darcy equation. The wormhole or extra wormhole is formed in the later period of oilfield development. After washing with water for a long period of time, the crude oil is almost completely driven out, which results in a single-phase flow in the wormhole or extra wormhole. The development effect is limited in the low permeability layers, and a two-phase flow exists. But the flow rate is low, and the Darcy's law is still obeyed in this region. Therefore, a single phase model is used to represent the flow rule in wormhole or extra wormhole which is full of water. The Forchheimer equation is usually used to represent the high speed Non-Darcy flow [10-14],

$$
-\frac{d P}{d L}=\frac{\mu}{k} v+\beta_{\mathrm{f}} \rho v^{2}
$$

Where, $p$ is injection-production pressure, $10^{-1} \mathrm{MPa} ; L$ is well spacing, $\mathrm{m} ; \mu$ is fluid viscosity, $\mathrm{mPa} \cdot \mathrm{s} ; \nu$ is flow velocity, $\mathrm{cm} / \mathrm{s} ; k$ is permeability, $\mu \mathrm{m}^{2} ; \rho$ is fluid density, $\mathrm{g} / \mathrm{cm}^{3} ; \phi$ is porosity, dimensionless; $\beta_{\mathrm{f}}$ is Non-Darcy coefficient, and modelled as [15-17],

$$
\beta_{\mathrm{f}}=0.005 /\left(\phi^{5.5} \cdot k^{0.5}\right)
$$

Forchheimer equation has a good theoretical basis. Because the similar form of Forchheimer equation can be derived from the Navier-Stokes equation [18-20]. The pressure drop in the equation is the sum of viscous resistance and inertia force. When the speed is low, the quadratic term is so small that it can be neglected, and the Forchheimer equation will be consistent with Darcy's law; when the speed is high, the pressure loss will be dominated by the quadratic term. All these features represent that using Forchheimer equation to describe high speed Non-Darcy flow is reasonable.

Belhaj et al. [21] presented the dimensionless parameter $B e$ to predict the high speed Non-Darcy flow. It is the ratio of quadratic term to linear term,

$$
B e=\frac{\beta_{\mathrm{f}} \rho v^{2}}{\mu v / k}=\frac{\beta_{\mathrm{f}} \rho k v}{\mu}
$$

Theoretically, when the flow rate is very small, it will be in Darcy regime; then, as the flow rate increases, the pressure gradient gradually deviates from linear Darcy equation and the nonlinear effect increases. So there is no critical value for a Darcy and non-Darcy flow. However, in order to differentiate the flow rules in the porous media, the $B e_{\mathrm{c}}=0.0526$ is mostly used as the critical value in field application [21], and this conclusion has been validated by the statistical results of field tests.

Zeng et al. [22] found that there are 53\% wells in the presence of wormhole in the $\mathrm{Ng}^{63+4}$ of Gudong Oilfield Block 7. And the permeability is as high as $8-80 \mu \mathrm{m}^{2}$, with the average value of $10 \mu \mathrm{m}^{2}$, which is 6.5 times higher than the initial value of $1.5 \mu^{2}$. The pore radius of wormhole is between 12 and $60 \mu \mathrm{m}$, with the average value of $20 \mu \mathrm{m}$, which is 3 times larger than the initial value of $6 \mu \mathrm{m}$.

In this paper, two injection-production well groups existing wormhole and extra wormhole in Gudong Oilfield are taken as an example. The parameters of injectionproduction well group are shown in Table 1. After a long period of water flooding, the wormhole is full of injected water, so the fluid viscosity and density can be given the value of $1 \mathrm{mPa} \cdot \mathrm{s}$ and $1 \mathrm{~g} / \mathrm{cm}^{3}$ respectively.

The $B e_{1}=0.5696$ and $B e_{2}=0.9655$ are obtained from the $E q .3$. According to the criterion of $B e_{\mathrm{c}}=0.0526$, the flow rule in the wormhole and extra wormhole belongs to a high speed Non-Darcy flow. Then, the Forchheimer equation and Darcy's law are both used to calculate the flow speed in the wormhole or extra wormhole, the results are shown in Table 2 .

Table 1. The Parameters of Injection-Production Well Group

\begin{tabular}{|c|c|c|c|c|c|}
\hline Wormhole type & Porosity & $\begin{array}{c}\text { Permeability } \\
/ \boldsymbol{\mu \mathbf { m } ^ { 2 }}\end{array}$ & $\begin{array}{c}\text { Well spacing } \\
/ \mathbf{m}\end{array}$ & $\begin{array}{c}\text { Pressure differential } \\
/ \mathbf{M P a}\end{array}$ & $\begin{array}{c}\text { Actual speed } \\
/(\mathbf{c m} / \mathbf{s})\end{array}$ \\
\hline \hline Wormhole & 0.3 & 10 & 279 & 20 & 0.156 \\
\hline Extra wormhole & 0.35 & 25 & 212 & 20 & 0.348 \\
\hline
\end{tabular}

Table 2. Calculation Results of Darcy and Non-Darcy Flow

\begin{tabular}{|c|c|c|c|c|}
\hline Wormhole type & $\begin{array}{c}\text { Actual speed } \\
/(\mathbf{c m} / \mathbf{s})\end{array}$ & $\begin{array}{c}\text { Non-Darcy flow } \\
/(\mathbf{c m} / \mathbf{s})\end{array}$ & $\begin{array}{c}\text { Error } \\
/ \%\end{array}$ & $\begin{array}{c}\text { Darcy flow } \\
/(\mathbf{c m} / \mathbf{s})\end{array}$ \\
\hline \hline Wormhole & 0.156 & 0.1542 & 1.15 & 53.14 \\
\hline Extra wormhole & 0.348 & 0.3428 & 1.49 & 0.2389 \\
\hline
\end{tabular}


It is clear that, the error between calculated speed and actual speed is very little based on the Forchheimer equation, but which is more than $50 \%$ in wormhole and $90 \%$ in the extra wormhole based on the Darcy's law. Therefore, it is reasonable that the Forchheimer equation is used to describe the flow rule in wormhole and extra wormhole.

\section{COMPARISONS OF FORCHHEIMER MODEL WITH OTHER MODELS}

\subsection{Exponent Model}

The idea of non-integer exponents for the relationship between pressure gradient and flow rate was introduced by White [23] and generalized by Missbach [24].

$v=-C\left(\frac{d P}{d L}\right)^{n}$

Where, $C$ is a constant, related to porous media and fluid properties, and it is assigned as $k / \mu$ in this paper; $n$ is the flow index, its value is between 0.5 and 1 .

\subsection{Mazaheri Model}

Mazaheri et al. [25] obtained a novel model to represent that the pressure drop increase deviates from the linear variation by fitting the simulation data,

$-\frac{d P}{d L}=\frac{\mu}{k} v+\frac{\rho}{\eta} v^{2}$

\subsection{Model Comparisons}

The well groups of Gudong Oilfield are taken as an example again. Then, the exponent model, Mazaheri model and Forchheimer model is used to predict the flow rate based on the reservoir parameters respectively. The results are shown in Table 3.
From Table 3, when the $n$ of exponent model equals 0.8 for wormhole and 0.7 for extra wormhole, the results are satisfactory, but the errors are large in other cases. The $n$ is difficult to be determined in the process of practical application. The errors of Mazaheri model are $24.27 \%$ and $8.45 \%$, which are both larger than that of the Forchheimer model. It can clearly be seen that the Forchheimer model is superior to the exponent model and Mazaheri model on representing the flow rules in wormhole or extra wormhole.

\section{PRODUCTIVITY EQUATION FOR POORLY CON- SOLIDATED RESERVOIR}

It is assumed that a positive rhythm reservoir with a total effective thickness $H$, the thickness of wormhole $h$, and the width of high permeability strip is $B$. The injectionproduction well spacing is $L$, and the injection-production pressure difference is $\Delta p$. The permeability of wormhole is $k_{\mathrm{w}}$, and the fluid viscosity and density are $\mu_{\mathrm{w}}$ and $\rho_{\mathrm{w}}$ respectively. The permeability of non-wormhole is $k_{\mathrm{n}}$, and the fluid viscosity and density are $\mu_{\mathrm{n}}$ and $\rho_{\mathrm{n}}$ respectively. Also, the one-dimensional displacement from injector to producer is assumed. The $B e_{\mathrm{c}}$ is also used to judge the flow rule, when the $B e$ in the wormhole is lower than $B e_{\mathrm{c}}$, the flow rule in the wormhole will transform into Darcy flow. The productivity of wormhole is,

$$
Q_{1}=v_{1} A_{1}= \begin{cases}B h\left(\frac{\sqrt{\left(\mu_{\mathrm{w}} / k_{\mathrm{w}}\right)^{2}+4 \rho_{\mathrm{w}} \beta_{\mathrm{f}} \frac{\Delta p}{\Delta L}}-\frac{\mu_{\mathrm{w}}}{k_{\mathrm{w}}}}{2 \rho_{\mathrm{w}} \beta_{\mathrm{f}}}\right) & B e \geq 0.0526 \\ \frac{k_{\mathrm{w}} B h \Delta p}{\mu_{\mathrm{w}} \Delta L} & B e<0.0526\end{cases}
$$

The productivity of non-wormhole is,

$Q_{2}=v_{2} A_{2}=\frac{k_{\mathrm{n}} B(H-h) \Delta p}{\mu_{\mathrm{n}} \Delta L}$

Table 3. Comparisons of Forchheimer Model with Exponent Model and Mazaheri Model

\begin{tabular}{|c|c|c|c|c|c|}
\hline Wormhole type & $\begin{array}{c}\text { Actual value } \\
/(\mathrm{cm} / \mathrm{s})\end{array}$ & Models & Parameter & Calculation value /(cm/s) & $\begin{array}{c}\text { Error } \\
1 \%\end{array}$ \\
\hline \multirow{8}{*}{ Wormhole } & \multirow{8}{*}{0.156} & \multirow{6}{*}{ Exponent model } & $n=0.5$ & 0.0892 & 42.79 \\
\hline & & & $n=0.6$ & 0.1087 & 30.34 \\
\hline & & & $n=0.7$ & 0.1323 & 15.17 \\
\hline & & & $n=0.8$ & 0.1611 & 3.30 \\
\hline & & & $n=0.9$ & 0.1962 & 25.79 \\
\hline & & & $n=1.0$ & 0.2389 & 53.17 \\
\hline & & \multicolumn{2}{|c|}{ Mazaheri model } & 0.1939 & 24.27 \\
\hline & & \multicolumn{2}{|c|}{ Forchheimer model } & 0.1542 & 1.15 \\
\hline \multirow{8}{*}{ Extra wormhole } & \multirow{8}{*}{0.348} & \multirow{6}{*}{ Exponent model } & $n=0.5$ & 0.2194 & 36.96 \\
\hline & & & $n=0.6$ & 0.2746 & 21.09 \\
\hline & & & $n=0.7$ & 0.3437 & 1.24 \\
\hline & & & $n=0.8$ & 0.4302 & 23.61 \\
\hline & & & $n=0.9$ & 0.5384 & 54.71 \\
\hline & & & $n=1.0$ & 0.6739 & 93.64 \\
\hline & & \multicolumn{2}{|c|}{ Mazaheri model } & 0.3185 & 8.45 \\
\hline & & \multicolumn{2}{|c|}{ Forchheimer model } & 0.3428 & 1.49 \\
\hline
\end{tabular}


Table 4. Yield Distributions of Wormhole and Non-Wormhole

\begin{tabular}{|c|c|c|c|c|}
\hline Darcy flow & 67.669 & 4.308 & 71.977 & 94.015 \\
\hline Non-Darcy flow & 43.123 & 4.308 & 47.431 & 90.917 \\
\hline
\end{tabular}

The total productivity is,

$$
Q_{\mathrm{t}}=Q_{1}+Q_{2}= \begin{cases}B h\left(\frac{\sqrt{\left(\mu_{\mathrm{w}} / k_{\mathrm{w}}\right)^{2}+4 \rho_{\mathrm{w}} \beta_{\mathrm{f}} \frac{\Delta p}{\Delta L}}-\frac{\mu_{\mathrm{w}}}{k_{\mathrm{w}}}}{2 \rho_{\mathrm{w}} \beta_{\mathrm{f}}}\right)+\frac{k_{\mathrm{n}} B(H-h) \Delta p}{\mu_{\mathrm{n}} \Delta L} & B e \geq 0.0526 \\ \frac{k_{\mathrm{n}} B H \Delta p}{\mu_{\mathrm{n}} \Delta L} & B e<0.0526\end{cases}
$$

Based on the tracer production curve of an well group in Gudong Oilfield, the thickness of wormhole is only several centimeters, but the permeability may reach up to $10-1000$ $\mu \mathrm{m}^{2}$. As a result, only $1-8 \%$ of the total effective thickness is occupied by the wormhole, but $90 \%$ of the production volume is occupied [26]. According to the field data, the well spacing is $266 \mathrm{~m}$. The total effective thickness is $2 \mathrm{~m}$, and the thickness of wormhole is $0.09 \mathrm{~m}$ which occupies $4.5 \%$ of the total effective thickness. The width is about $1 \mathrm{~m}$. The oil viscosity is $50 \mathrm{mPa} \cdot \mathrm{s}$, and the injection-production pressure differentce equals $20 \mathrm{MPa}$. The permeability of wormhole is $10 \mu \mathrm{m}^{2}$, and the permeability of non-wormhole is $1.5 \mu \mathrm{m}^{2}$. The porosity is 0.3 . The yields of wormhole and non-wormhole are calculated by the Eqs. 6 and 7, and the results are shown in Table 4.

It is shown that the wormhole thickness occupies $4.5 \%$ of the total effective thickness, but the yield percentage reaches up to $90.917 \%$. This result is consistent with the statistical value in the oilfield, which proves the rationality of using Forchheimer equation to represent the flow rule in wormhole or extra wormhole once again.

\section{SENSITIVE ANALYSIS AND IMPROVEMENT MEASURES FOR DEVELOPMENT OF POORLY CONSOLIDATED RESERVOIR}

\subsection{Viscosity of Displacing Fluid}

Increasing the viscosity of displacing fluid is an emphasis for enhancing oil recovery, and it is also important for developing the poorly consolidated reservoirs. In fact, it is only the displacing fluid in the wormhole, but a mixed system of displacing fluid and crude oil in the nonwormhole. Then, the effect of viscosity ratio of crude oil to displacing fluid on yield percentage of wormhole is studied based on the productivity equation, and as shown in Fig. (2).

It is shown that the viscosity ratio of crude oil to displacing fluid has a significant effect on the yield distribution. As the viscosity ratio increases, the yield percentage of wormhole increases rapidly. When the viscosity ratio of crude oil to displacing fluid equals 1 , the yield percentage in non-wormhole can increase to about $85 \%$, a large number of remaining oil will be producted. Therefore, the EOR technology such as polymer flooding and cross-linked polymer flooding can be used to develop the poorly consolidated reservoirs in high water-cut stage.

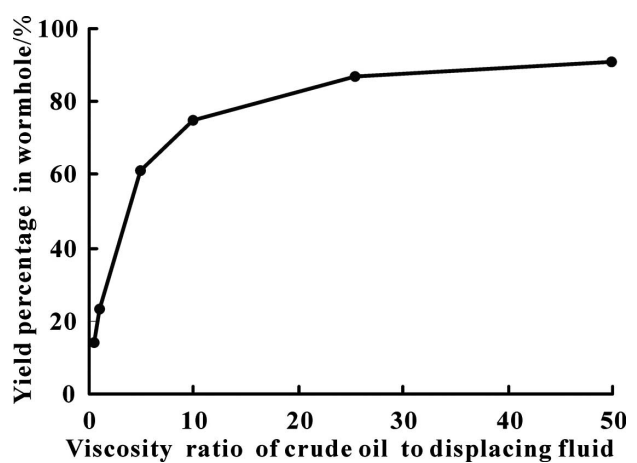

Fig. (2). Effect of viscosity ratio of oil to displacing fluid on yield percentage in wormhole.

\subsection{Permeability of Wormhole}

The main reason for the high flow speed in the wormhole is the excessive permeability. And it also affect the heterogeneity of injection profile. The effect of permeability ratio of wormhole to non-wormhole on yield percentage is studied based on the productivity equation, and as shown in Fig. (3).

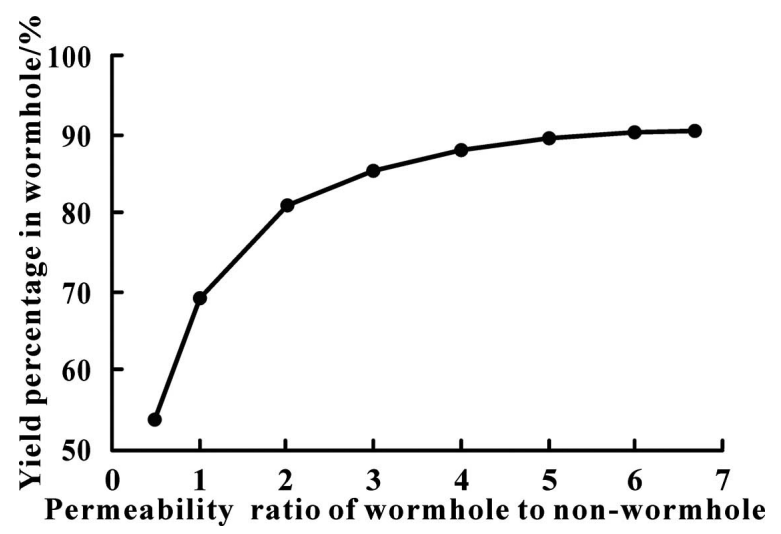

Fig. (3). Effect of permeability ratio of wormhole to non-wormhole on yield percentage in wormhole.

It is shown that the permeability ratio of wormhole to non-wormhole also has a significant effect on the yield distribution. As the permeability ratio increases, the yield percentage of wormhole increases. When the ratio of wormhole to non-wormhole equals 1 , the yield percentage in non-wormhole can increase up to about 30\%. Therefore, the EOR technology such as body gel blocking, pre-gelled particles flooding and foam flooding can be used to develop the poorly consolidated reservoirs in high water-cut period. 


\subsection{Inject-Production Pressure Gradient}

Adjusting the operation parameters is another way to enhance oil recovery. In this section, the effect of injectionproduction pressure gradient is discussed. The effect of injection-production pressure gradient on yield percentage is shown in Fig. (4).

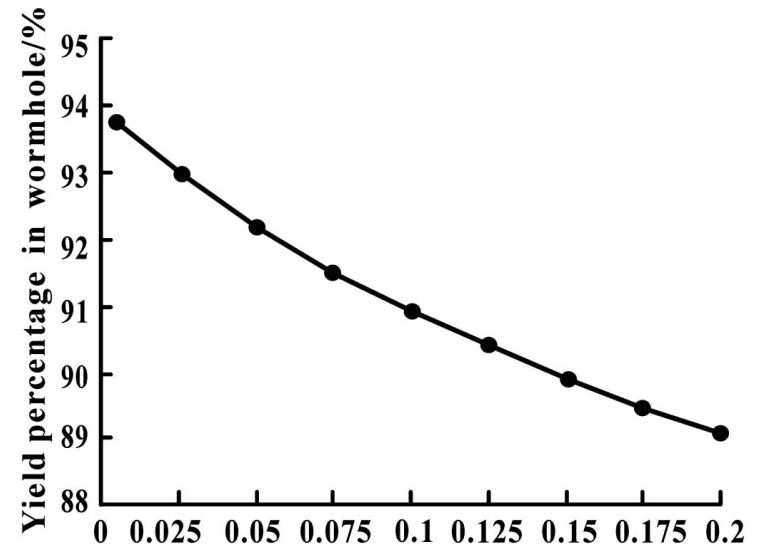

Inject-production pressure gradient $/\left(10^{-1} \mathrm{MPa} / \mathrm{m}\right)$

Fig. (4). Effect of inject-production pressure gradient on yield percentage in wormhole.

It is shown that the influence degree of injectionproduction pressure gradient is weak. As the injectionproduction pressure gradient increases, the yield percentage of wormhole reduces gradually. Therefore, a larger pressure differential should be used in the development process if the condition is permitted.

\section{CONCLUSIONS}

The flow rule in the wormhole or extra wormhole can be regarded as a high speed Non-Darcy flow, and modelled by the Forchheimer equation. And it is superior to the exponent model and Mazaheri model. The productivity equation is obtained based on the Forchheimer equation. and then the sensitivity analysis of viscosity ratio of crude oil to displacing fluid, permeability ratio of wormhole to nonwormhole and injection-production pressure gradient are studied,

- The viscosity ratio of crude oil to displacing fluid has a significant effect on the yield distribution, as the viscosity ratio increases, the yield percentage of wormhole increases rapidly. Polymer flooding or crosslinked polymer flooding can be used to develop the poorly consolidated reservoirs in high water-cut stage;

- The permeability ratio of wormhole to non-wormhole has a significant effect on the yield distribution. As the permeability ratio increases, the yield percentage of wormhole increases. But the influencing degree is much weaker than that of viscosity ratio. Body gel blocking, pre-gelled particles flooding and foam flooding can be used to develop the poorly consolidated reservoirs with wormhole or extra wormhole.

- The injection-production pressure gradient has the weakest influence on the yield distribution. As the injection-production pressure gradient increases, the yield percentage of wormhole reduces gradually. But it is also necessary to use a larger pressure difference in the development process if the condition is permitted.

\section{CONFLICT OF INTEREST}

The authors confirm that this article content has no conflicts of interest.

\section{ACKNOWLEDGEMENTS}

This study is funded by National Science \& Technology Major Projects of China (2011ZX05014-003-008HZ) and National Program on Key Basic Research Project (973 Program) (2011CB201006-06).

\section{REFERENCES}

[1] L.F. Zeng, Study on the Mechanism of Big Channel Formation and Porous Flow Theory in Unconsolidated Sandstone reservoir. University of Petroleum Press: China, 2002.

[2] Z.L. Dou, L.F. Zeng, Z.H. Zhang, W. Xiong, G.L. Tian, X.W. Liu, and L.X. Huang, "Research on the diagnosis and description of wormhole", Petroleum Exploration and Development, vol. 28, no. 1, pp. 75-77, 2001.

[3] C. He, P. Li, Z.Y. Wang, R.L. Jing, Q.Y. Xu, and Q. Yin, "The characteristics of large pore path in Gudao Oilfield and its profile control or plugging method", Petroleum Drill \& Produce Technology, vol. 22, no. 5, pp. 63-66, 2000.

[4] S.Y. Hu, L.H. Zhang, H.S. Yao, X.F. Zhang, and J.P. Sun, "A simulation method for big channel formation in unconsolidated sandstone reservoir during water-flooding", In: Petroleum Society's $7^{\text {th }}$ Canadian International Petroleum Conference $\left(57^{\text {th }}\right.$ Annual Technical Meeting), June 13-15, Calgary, Alberta: Canada, 2006.

[5] A. McDiarmid, I. Alexander, and A. Ion, "Experience of a reservoir waterflood failure and remediation treatment in the Stag Reservoir, Australia", In: The SPE Asia Pacific Improved Oil Recovery Conference, 8-9 October, Kuala Lumpur, Malaysia, 2001.

[6] B. Izgec, and C.S. Kabir, "Identification and characterization of high-conductive layers in waterfloods", SPE Reservoir Evaluation \& Engineering, vol. 14, no. 1, pp. 113-119, 2011.

[7] L.C.B. Bianco, S. Petrobras, and P.M. Halleck, "Mechanisms of arch instability and sand production in two-phase saturated poorly consolidated sandstones", In: SPE European Formation Damage Conference, Hague: Netherlands, 2001.

[8] Z.M. Du, W. Jiang, and Z.H. Chen, "A new integrated model to simulate the disturbed zone in CHOPS: spread and erosion", In: presentation at the SPE Production and Operations Symposium, 48 April 2009, Oklahoma City: Oklahoma 2009.

[9] I. Vardoulakis, M. Stavropoulou, and P. Papanastasiou, "Hydromechanical aspects of the sand production problem", Transport in Porous Media, vol. 22, no. 2, pp. 225-244, 1996.

[10] P. Forchheimer, "Wasserbewegung durch Boden", ZVDI, vol. 45, pp. 1781-1788, 1901.

[11] D. Cornell, and D.L. Katz, "Flow of gases through consolidated porous media", Industrial and Engineering Chemistry, vol. 45, pp. $2145,1953$.

[12] H. Huang, and J. Ayoub, "Applicability of the Forchheimer equation for non-Darcy flow in porous media", SPE Journal, vol. 13, no. 1, pp. 112-122, 2008.

[13] S.C. Jones, "Using the inertial coefficient, $\beta$, to characterize heterogeneity in reservoir rock. SPE 16949" In: 62 $2^{\text {nd }}$ Annual Technical Conference and Exhibition of the Society of Petroleum Engineers, September 27-30, Dallas, TX, 1987.

[14] D. Li, R.K. Svec, T.W. Engler, and R.B. Grigg, "Modeling and simulation of the wafer Non-Darcy flow experiments". In: SPE 68822, the 2001 SPE Western Regional Meeting, March 26-30, Bakersfield: CA, 2001.

[15] J. Geertsma, "Estimating the coefficient of inertial resistance in fluid flow through porous media", SPE Journal, vol. 14, no. 5, pp. 445-450, 1974.

[16] M.T. Balhoff, and M.F. Wheeler, "A predictive pore-scale model for Non-Darcy flow in porous media”, SPE Journal, vol. 14, no. 4, pp. 579-587, 2009.

[17] D. Li, and W.E. Thomas, "Literature review on correlations of the Non-Darcy coefficient", SPE70015, In: SPE Permian Basin Oil and Gas Recovery Conference, 15-16 May, Midland: Texas, 2001. 
[18] R.P. Chhabra, J. Comiti, I. Machač, "Flow of non-darcy fluids in fixed and fluidised beds", Chemical Engineering Science, vol. 56, no. 1, pp. 1-27, 2001.

[19] D. Ruth, and H.P. Ma, "On the derivation of the Forchheimer equation by means of the averaging theorem", Transport in Porous Media, vol. 7, no. 3, pp. 255-264, 1992.

[20] S. Whitaker, "The Forchheimer equation: A theoretical development", Transport in Porous Media, vol. 25, no. 1. pp. 2761, 1996.

[21] H.A. Belhaj, K.R. Agha, A.M. Nouri, S.D. Butt, H.F. Vaziri, and M.R. Islam, « Numerical simulation of non-Darcy flow utilizing the new Forchheimer's diffusivity equation", Society of Petroleum Engineers, p. 81499, 2003.

[22] L.F. Zeng, B.P. Chen, X.Z. Liu, "Preliminary study on quantitative description of high capacity channel in loose sandstone reservoir",
Petroleum Geology and Recovery Efficiency, vol. 9, no. 4, pp. 5354, 2002.

[23] A.M. White, "Pressure drops and loading velocities in packed towers", Transactions of the American Institute of Chemical Engineers, vol. 31, pp. 390-408, 1935.

[24] A. Missbach, "Listy cukrovar", vol. 55, p. 293, 1937.

[25] A.R. Mazaheri, B. Zerai, G. Ahmadi, J.R. Kadambi, B.Z. Saylor, M. Oliver, G.S. Bromhal, and D.H. Smith, "Computer simulation of flow through a lattice flow-cell model", Advances in Water Resources, vol. 28, pp. 1267-1279, 2005.

[26] X.Z. Wang, "High-capacity channel features of the high water-cut stage in the Gudong Oilfield", West China Petroleum Geosciences, vol. 2, no. 1, pp. 101-105, 2006.

Received: April 05, 2012

Revised: July 06, 2012

Accepted: July 20, 2012

(C) Jing and Huiqing; Licensee Bentham Open.

This is an open access article licensed under the terms of the Creative Commons Attribution Non-Commercial License (http://creativecommons.org/licenses/by-nc/3.0/) which permits unrestricted, non-commercial use, distribution and reproduction in any medium, provided the work is properly cited. 